\title{
Sand mining and morphometric dynamics along Ologe Lagoon
}

\author{
DELIMA THADDEUS ${ }^{1}$ \& SHAKIRUDEEN ODUNUGA ${ }^{2}$ \\ 1 Department of Geography, Adeniran Ogunsanya College of Education Otto/Ijanikin, Lagos, Nigeria \\ thaddelima1@gmail.com \\ 2 Department of Geography, University of Lagos, Akoka Lagos Nigeria
}

The study focuses on the sand mining activities and morphometric dynamics of Ologe Lagoon, in Lagos, Nigeria. It determines the sand mining activities and morphometric dynamics of Ologe Lagoon catchment area, the quantity of sand mined per unit time, and the extent of environmental degradation due to the continuous sand mining activities. Topographic maps of the 1985 and 2013 Ikonos satellite imagery were used to identify the morphometric dynamics of the area.

Two hypotheses were generated to determine if there are significant differences between the means of the sampled population that lost properties due to flooding, and to determine if there was a correlation between building subsidence and loss of property; it was tested using Analysis of Variance (ANOVA) with a correlation coefficient at $0.05 \alpha$ significance level. The results of geometric measurement of the Ologe Lagoon between the two years interval show that perimeter width and circularity of the basin had reduced and shrunk, while the form factor remains the same at $0.15 \mathrm{~km}^{2}$. The basin elongation increased significantly by $0.01 \mathrm{~km}^{2}$, thus, increasing the rate at which water will be supplied to the lagoon. The ration of the form factor of $0.69 / 0.5$ is close to the unity value R1, which shows a higher peak runoff; the values of the circularity ratio of 3.94/3.13 indicates circularity. This shows that the basin is circular time.

The impact of the geometry indicates the development of mud flats and sandy bars, particularly at the lower portion of the lagoon; there is also modification of sediment deposition. The anthropogenic activity of sand mining causes destruction of the riparian forest around the lagoon. There is no significant difference in the means of sampled respondents regarding loss properties due to flooding, while there is a correlation between building subsidence and loss of life. It is recommended that a road map should be developed and implemented by the relevant agency of the government to guide anthropogenic activities around the lagoon to enhance sustainable development. 